\title{
Stability Indicating Method for Determination of Benznidazole and Its Degradation Products in Active Pharmaceutical Ingredient
}

\author{
Wilton H. Kawaguchi, ${ }^{a}$ Mariana M. Fachi, ${ }^{a}$ Leticia B. Cerqueira,${ }^{a}$ Michel L. Campos, ${ }^{b}$ \\ Alan G. Gonçalves, ${ }^{a}$ Angela C. L. B. Trindade, ${ }^{a}$ Iara J. M. Reason ${ }^{c}$ and \\ Roberto Pontarolo ${ }^{(} *, a$
}

${ }^{a}$ Departamento de Farmácia, Universidade Federal do Paraná, Av. Lothário Meissner, 632, 80210-170 Curitiba-PR, Brazil

${ }^{b}$ Instituto de Ciências da Saúde, Universidade Federal do Mato Grosso, 78550-728 Sinop-MT, Brazil

${ }^{c}$ Laboratório de Imunopatologia Molecular, Departamento de Patologia Clínica, Universidade Federal do Paraná, 80069-240 Curitiba-PR, Brazil

\begin{abstract}
Currently, treatment of Chagas disease is restricted to the use of benznidazole and nifurtimox; however, nifurtimox was temporarily suspended in some countries. Based on the limitations in pharmacological treatments, it is essential to guarantee the quality of benznidazole. Therefore, this work aimed to identify the degradation products of benznidazole and to validate a stability indicating method. The stability test was performed through a forced degradation study, exposing benznidazole under a range of conditions. Benznidazole proved to be unstable under acidic and alkaline conditions, and three products were identified by liquid chromatography coupled to a hybrid quadrupole time-of-flight mass spectrometer (UPLC-QTOF-MS). Furthermore, a stability indicating method by high performance liquid chromatography with a diode array detector (HPLC-DAD) for benznidazole was developed and validated according to ICH (International Conference on Harmonisation) and ANVISA (Agência Nacional de Vigilância Sanitária) guidelines. The method was linear (180-420 $\mu \mathrm{g} \mathrm{mL}^{-1}$ range), selective in the presence of degradation products, precise (relative standard deviation $(\mathrm{RSD})<0.6 \%$ ), accurate (recovery $>99.2 \%$ ), robust, and free of matrix effects. The method was successfully able to quantify the benznidazole in pharmaceutical formulations.
\end{abstract}

Keywords: benznidazole, Chagas disease, degradation products, stability indicating method

\section{Introduction}

Chagas disease, which is caused by the parasite Trypanosoma cruzi, is considered a neglected disease and a public health problem. ${ }^{1-3}$ According to the World Health Organization, about eight million people worldwide are affected by this pathology, and the majority of individuals live in Latin America. ${ }^{1,45}$ The disease occurs in two phases: the acute and chronic phases. The early phase of the pathology can be lethal in many cases, with intense parasite multiplication and cell invasion. Usually, the individual affected at this stage is asymptomatic or with symptoms common to any infection. The chronic phase of the disease is characterized by impairment of the digestive and/or cardiac system. ${ }^{6-9}$

*e-mail: pontarolo@ufpr.br
After confirmation by diagnosis, immediate pharmacological treatment of the disease is recommended. Currently available therapeutic options include two nitroheterocyclic drugs: benznidazole (BNZ) and nifurtimox. However, in some countries only BNZ has been approved because of the lower efficacy of nifurtimox compared to benznidazole and because of the severe adverse events caused by nifurtimox..$^{10-12}$ To guarantee the quality of benznidazole, thus maintaining its efficacy and safety, it is crucial to have strict control of the drug stability. ${ }^{13}$

In this context, to ensure the integrity of benznidazole and its pharmaceutical form content within the specific limits, under the influence of environmental factors as a function of time, it is recommended to perform stability studies. Among stability studies, studies of forced degradation provide an approach for the identification of the possible degradation products that can form in accelerated 
or long-term stability studies. ${ }^{13-16}$ Furthermore, to monitor the possible changes in benznidazole over time, an indicative stability method is required to quantify this drug without interference from degradation products, impurities, and excipients. ${ }^{13,15}$ Considering that there are only studies of thermal, ${ }^{17}$ and photostability, ${ }^{18}$ the objective of the present work was to detect and suggest the degradation products derived from benznidazole by ultra-performance liquid chromatography coupled to a hybrid quadrupole time-of-flight mass spectrometer (UPLC-QTOF-MS) and to develop and validate a stability indicating method for benznidazole by high performance liquid chromatography with a diode array detector (HPLC-DAD).

\section{Experimental}

\section{Chemicals and reagents}

The active pharmaceutical ingredient of benznidazole (99.1\%) was kindly donated by the Pharmaceutical Laboratory of the State of Pernambuco, Recife, Brazil. The structure of this substance is shown in Figure 1. Benznidazole tablets (100 mg) were kindly supplied by the Paraná Medicines Center, Cemepar, Curitiba, Brazil.

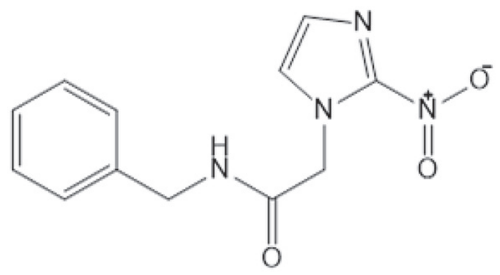

Figure 1. Chemical structure of benznidazole.

High-performance liquid chromatography grade acetonitrile was acquired from Panreac (Barcelona, Spain). Sodium hydroxide (99\%) and hydrochloric acid (36.5\%) were obtained from Merck (Darmstadt, Germany) and Vetec (Duque de Caxias, Brazil), respectively. Ammonium formate $(97 \%)$ and formic acid (> 98\%) were provided by Sigma-Aldrich (St. Louis, USA). Hydrogen peroxide (30\%) was acquired by Synth Labs (Diadema, Brazil). Ultrapure water was obtained from a Milli-Q instrument (Millipore Corp., Bedford, MA, USA).

\section{Preparation of stock and working solutions}

A stock solution of BNZ was prepared at a concentration of $5 \mathrm{mg} \mathrm{mL}^{-1}$, using acetonitrile as a diluent. The working solution was prepared by diluting aliquots from the stock solution with acetonitrile and water mixture $(50: 50, \mathrm{v} / \mathrm{v})$ to obtain a concentration of $1 \mathrm{mg} \mathrm{mL}^{-1}$.

\section{Sample preparation of pharmaceutical dosage forms}

Ten tablets were weighed to determine the average weight. Then, the powder equivalent to $10 \mathrm{mg}$ of BNZ was dissolved in acetonitrile up to $10 \mathrm{~mL}$ in a volumetric flask. The sample was filtered through a $0.22 \mu \mathrm{m}$ polyvinylidene difluoride (PVDF) membrane filter. Then, the sample was diluted with acetonitrile and water (50:50, $\mathrm{v} / \mathrm{v})$ to achieve a final concentration of $300 \mu \mathrm{g} \mathrm{mL}$ benznidazole.

\section{HPLC-DAD instrumentation and conditions}

HPLC-DAD analysis was performed with an Agilent 1100 HPLC (Santa Clara, United States) system that consisted of a quaternary pump G1311A, degasser G1379A, column thermostat G1316A, autosampler manager G1329A, and diode array detector G1315B. In addition, ChemStation ${ }^{\circledR}$ software, version A.10.02, was used.

The separation of BNZ and its degradation products was achieved on an XBridge ${ }^{\mathrm{TM}} \mathrm{C} 8$ column $(150 \times 4.6 \mathrm{~mm}, 5 \mu \mathrm{m})$ from Waters Corporation (Milford, United States). The column temperature was kept at $40{ }^{\circ} \mathrm{C}$. The mobile phase consisted of $20 \mathrm{mM}$ ammonium formate ( $\mathrm{pH}$ adjusted to 3.0 with formic acid) (solvent A) and acetonitrile (solvent B). The elution order was as follows: $0.00-15.00 \mathrm{~min}, 10$ to $90 \%$ B; $15.00-15.10 \mathrm{~min}, 90$ to $10 \% \mathrm{~B}$; and $15.10-20.00 \mathrm{~min}$, $10 \% \mathrm{~B}$. The flow rate was $1000 \mu \mathrm{L} \mathrm{min}{ }^{-1}$ and the injection volume was $20 \mu \mathrm{L}$. The detection wavelength was set at $320 \mathrm{~nm}$.

Instrumentation and conditions for detection of degradation products by UPLC-QTOF-MS

The identification of degradation products was conducted using an ultra-performance liquid chromatograph (Acquity H-Class, Waters Co., Milford, USA) coupled to a hybrid quadrupole time-of-flight mass spectrometer (Xevo G2-S, Waters Co., Milford, USA). Chromatographic separation was performed using an Acquity C8 column $(100 \times 2.1 \mathrm{~mm}, 1.7 \mu \mathrm{m}$, Waters Co., Milford, USA) maintained at $40^{\circ} \mathrm{C}$. The mobile phase was composed of water and acetonitrile, both containing $0.1 \%$ formic acid. The following gradient elution at a constant flow rate of $500 \mu \mathrm{L} \mathrm{min}{ }^{-1}$ was used: $0.00-3.40 \mathrm{~min}, 10$ to $90 \% \mathrm{~B}$; $3.40-3.50 \mathrm{~min}, 90$ to $10 \% \mathrm{~B}$; and 3.50-6.00 min, $10 \% \mathrm{~B}$. The injection volume was $3 \mu \mathrm{L}$.

The analysis was performed in positive and negative electrospray ionization modes with a capillary voltage of $3 \mathrm{kV}$, a cone voltage of $40 \mathrm{~V}$, and a source offset of $80 \mathrm{~V}$. The source temperature and desolvation temperature were 150 
and $350{ }^{\circ} \mathrm{C}$, respectively. The cone gas flow was $50 \mathrm{~L} \mathrm{~h}^{-1}$ and the desolvation gas flow was $400 \mathrm{~L} \mathrm{~h}^{-1}$. Nitrogen was used as the cone and desolvation gas, and argon was used as the collision gas.

Mass spectrometry data was collected from $\mathrm{m} / \mathrm{z} 50$ to 500 in $\mathrm{MS}^{\mathrm{E}}$ mode, allowing the identification of the compounds through the data acquisition in a data independent analysis mode. In this mode the MS analysis is performed alternating between low and high collision energies, after that precursor ions and their respective product ions are obtained by synchronizing the spectra. Data acquisition was done in centroid mode using MassLynx ${ }^{\mathrm{TM}}$ NT4.1 software. ${ }^{19}$ During the analysis, accurate mass was corrected using leucine enkephalin as lock mass at a flow rate of $20 \mu \mathrm{L} \mathrm{min}{ }^{-1}$.

Furthermore, to predict and confirm the forced degradation pathways the Zeneth software, version 7.1.3 (Copyright@ Lhasa Limitee) was used. ${ }^{20}$

\section{Forced degradation study}

Forced degradation conditions were carried out according to the guidelines of Agência Nacional de Vigilância Sanitária (ANVISA) ${ }^{21}$ and the International Conference on Harmonisation (ICH). ${ }^{22}$ The tested conditions can be seen in the following sections.

\section{Acidic and alkaline conditions}

For the acidic and alkaline degradation, BNZ $\left(1 \mathrm{mg} \mathrm{mL}{ }^{-1}\right)$ was diluted with different concentrations of hydrochloric acid and $0.1 \mathrm{M}$ sodium hydroxide, respectively. These solutions were kept in a water bath at $60{ }^{\circ} \mathrm{C}$ for $96 \mathrm{~h}$ for the acid solution and $12 \mathrm{~h}$ for the alkaline solution. After the specified times, each solution was neutralized by adjusting the $\mathrm{pH}$ to 7.0 and diluted with acetonitrile and water $(50: 50, \mathrm{v} / \mathrm{v})$ to obtain $300 \mu \mathrm{g} \mathrm{mL}^{-1}$ of analyte for HPLC-DAD analysis and $500 \mathrm{ng} \mathrm{mL}^{-1}$ for UPLC-QTOF-MS analysis.

\section{Thermal condition}

Working solutions of BNZ were diluted with distilled water and placed in a water bath at 60 and $80^{\circ} \mathrm{C}$ for 7 days. Then, the solution was diluted, resulting in the following concentrations: $300 \mu \mathrm{g} \mathrm{mL} \mathrm{m}^{-1}$ for HPLC-DAD injection and $500 \mathrm{ng} \mathrm{mL}^{-1}$ for UPLC-QTOF-MS.

\section{Oxidation condition}

The working solution of benznidazole was treated with $3 \%$ hydrogen peroxide and placed in a water bath at room temperature for $48 \mathrm{~h}$. After 7 days, the solution was diluted with acetonitrile and water $(50: 50, \mathrm{v} / \mathrm{v})$ to achieve a final concentration of $300 \mu \mathrm{g} \mathrm{mL} \mathrm{L}^{-1}$ for HPLC-DAD and $500 \mathrm{ng} \mathrm{mL}^{-1}$ for UPLC-QTOF-MS.

\section{Photolytic degradation}

Photodegradation was studied by placing working solutions of benznidazole in the following conditions: a chamber containing a cool white fluorescent lamp output similar to that specified in ISO $10977^{23}$ and a near UV fluorescent bulb having a spectral wavelength from 320 to $400 \mathrm{~nm}$ in concordance with the guidelines of ANVISA $^{24}$ and ICH. ${ }^{25}$ This solution was maintained in these condition for 14 days and was diluted to achieve a final concentration of $300 \mu \mathrm{g} \mathrm{mL} \mathrm{m}^{-1}$ for the HPLC-DAD analysis and $500 \mathrm{ng} \mathrm{mL}^{-1}$ for UPLC-QTOF-MS.

\section{Method validation}

The proposed stability indicating method for the quantification of BNZ in the presence of the degradation products (DP) was validated according to ANVISA $^{26}$ and ICH guidelines. ${ }^{27}$ The following parameters were considered: selectivity, linearity, accuracy, precision, and robustness.

\section{Selectivity}

To evaluate the method selectivity, benznidazole was submitted to stress conditions (acid, alkaline, thermal, oxidative, and photolytic conditions) at a concentration of $1000 \mu \mathrm{g} \mathrm{mL} \mathrm{mL}^{-1}$. The ability of the method to differentiate $\mathrm{BNZ}$ in the presence of possible product degradation was assessed through determination of purity BNZ peaks in HPLC-DAD. The scanning was performed in the range of 200-400 nm.

\section{Linearity}

The linearity of the method was tested from triplicates of the calibration curve containing five levels of concentration $\left(180,240,300,360\right.$, and $\left.420 \mu \mathrm{gL}^{-1}\right)$. Samples were prepared by diluting the stock solution with a mixture of acetonitrile and water $(50: 50, \mathrm{v} / \mathrm{v})$. The linearity between variables was measured through correlation coefficients (r), determination $\left(r^{2}\right)$, and slopes. Beyond that, for the linearity assessment, the test of equality of variance and homoscedasticity (as null hypothesis) were evaluated through Cochran's C test, and the statistical significance of the slope coefficients of the lines was also established by analysis of variance (ANOVA) and $F$ test (considering $5 \%$ level of significance).

\section{Limit of quantification}

The limit of quantitation (LOQ) was estimated based on the parameters of the calibration curve using the following 
calculation: 10 times the standard deviation of the response divided by the slope of the standard curve. Moreover, the precision of the lower concentration of the calibration curve and its signal-to-noise ratio were measured.

\section{Precision}

The precision of the method was determined through intra-day and inter-day precision. To perform intra-day precision, six solutions at $300 \mu \mathrm{g} \mathrm{mL}^{-1}$ were prepared by the same analyst and analyzed by the same equipment in a short period of time. The inter-day precision was performed by analyzing six solutions in the same concentration level; however, analysis was performed by another analyst on the same equipment in two non-consecutive days. The precision was evaluated by relative standard deviation (RSD) and Student's $t$-test.

\section{Accuracy}

To assess this parameter, the standard addition method was used. Nine samples (prepared according to "Sample preparation of pharmaceutical dosage forms" sub-section) were diluted to achieve $30 \mu \mathrm{g} \mathrm{mL} L^{-1}$. Then, the samples were spiked with the stock solution of BNZ to obtain the following concentrations: 240,300 , and $360 \mu \mathrm{g} \mathrm{mL} \mathrm{m}^{-1}$. The percentage recovery was measured by comparing the spiked samples with standard solutions at the same concentration, which represented $100 \%$ recovery.

\section{Robustness}

To perform the robustness tests, benznidazole solutions $\left(300 \mu \mathrm{g} \mathrm{mL}^{-1}\right)$ were prepared in triplicate. Some chromatographic parameters were changed for the evaluation of this parameter, such as the $\mathrm{pH}$ of the mobile phase (from 3.0 to 2.9 and 3.1), the initial mobile phase gradient (from $\mathrm{A}: \mathrm{B}, 90: 10$ to $\mathrm{A}: \mathrm{B}, 89: 11$ and 91:9), the temperature (from 40 to 39 and $41^{\circ} \mathrm{C}$ ), the mobile phase flow (from 1 to 0.9 and $1.1 \mathrm{~mL} \mathrm{~min}^{-1}$ ), and the injection volume (from 20 to 19.9 and $20.1 \mu \mathrm{L}$ ). The RSD and the statistical $F$ tests and Student's $t$-test were used to evaluate the behavior of the benznidazole against these small changes.

\section{Matrix effect}

The matrix effect was determined by comparing the slopes of two analytical curves. The first curve was constructed with the standard solution and the second with the diluted samples spiked with the analyte, both in the same concentrations (from 180 to $420 \mu \mathrm{g} \mathrm{mL}^{-1}$ ). To evaluate this parameter, a significance level of 5\% was adopted in the null hypothesis test, and Excel software ${ }^{28}$ with the ActionStat supplement was used.

\section{Results and Discussion}

\section{Optimization of chromatography conditions}

To achieve the best chromatographic profile of benznidazole and its degradation products, different conditions were tested to separate the analyte of interest from their DPs. The chromatogram obtained under the defined conditions is shown in Figure 2.

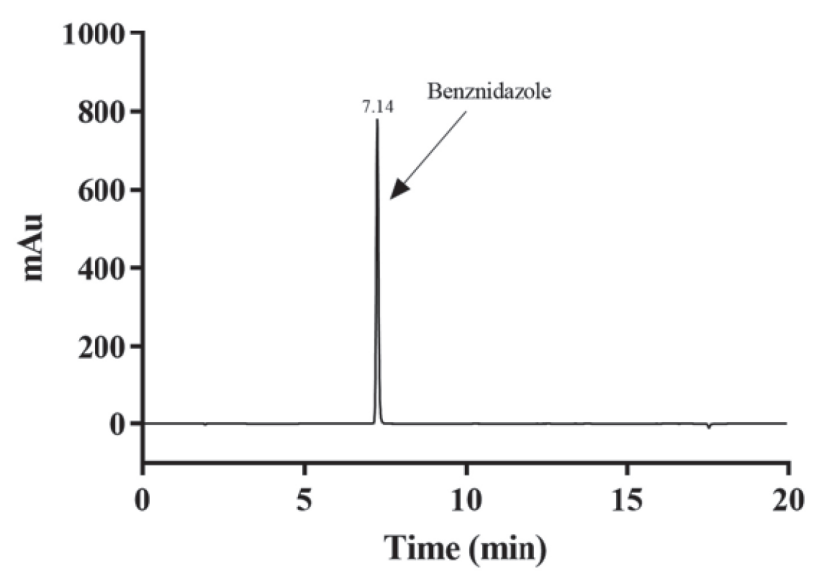

Figure 2. Chromatogram obtained for benznidazole after chromatographic optimization in HPLC-DAD (300 $\mathrm{ng} \mathrm{mL}^{-1}$ benznidazole was diluted in $50: 50 \mathrm{v} / \mathrm{v}$ acetonitrile and water).

\section{Forced degradation study}

\section{Alkaline condition}

Benznidazole was submitted to degradation under the alkaline condition, as outlined in "Acidic and alkaline conditions" sub-sub-section, and the sample was analyzed by the HPLC-DAD method. A significant decreasing (50\%) in the peak area of BNZ was observed. In addition, the appearance of a new peak at $1.93 \mathrm{~min}$ also was noted (see Figure S1a, in Supplementary Information (SI) section).

The same sample was then further investigated by means of an UPLC-QTOF-MS ${ }^{\mathrm{E}}$ analysis. This analysis indicated that the additional chromatographic peak found for the previous HPLC-DAD analysis was in fact constituted by two compounds, which were detected in positive mode at the retention times of $2.08 \mathrm{~min}$ (DP1) and $2.15 \mathrm{~min}$ (DP2), both referring to molecular ion $\mathrm{m} / \mathrm{z}, 232.1080$ (Figure 3).

To investigate the differences between DP1 and DP2, the respective product ions from the collision induced dissociation in high energy were compared. The same fragmentation profile was observed for both molecules; therefore, we suggest that they were closely related tautomeric compounds with a molecular formula of $\mathrm{C}_{12} \mathrm{H}_{13} \mathrm{~N}_{3} \mathrm{O}_{2}$ and named $N$-benzyl-2-(2-hydroxy$1 \mathrm{H}$-imidazol-1-yl)acetamide (DP1) and $\mathrm{N}$-benzyl- 


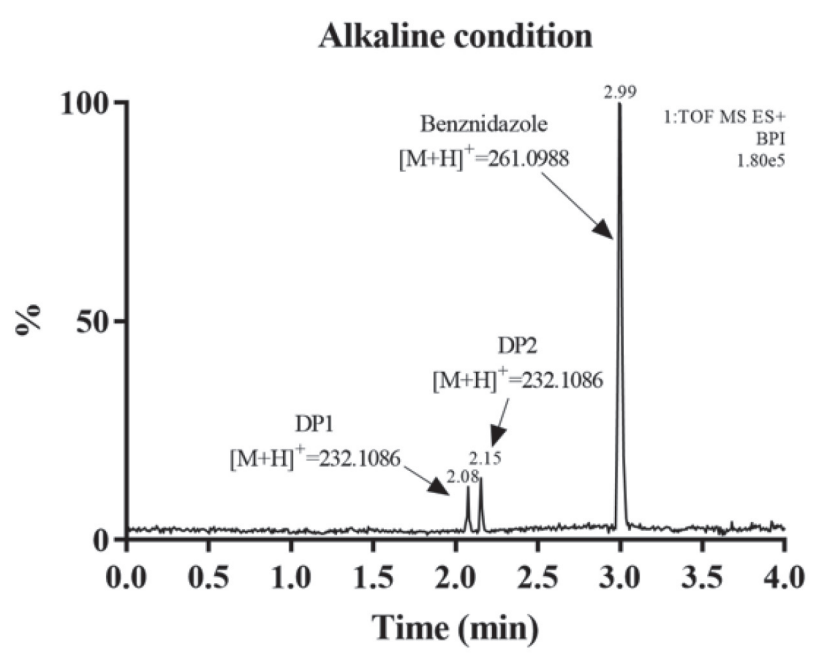

Figure 3. Chromatogram obtained for benznidazole after alkaline condition in UPLC-QTOF-MS ${ }^{\mathrm{E}}$.

2-(2-oxo-2,3-dihydro-1H-imidazol-1-yl)acetamide (DP2). The proposed DP1 and DP2 structures and the pathway of degradation are shown in Figure 4.

The formation of DP1 and DP2 could be explained by the nucleophilic attack of the hydroxide anion onto the electron deficient carbon of the imidazole ring. The aromatization of the imidazole ring would result into the nitrite group displacement, and formation of the hydroxylated degradation product DP1. Tautomerism of the amide-iminol type of derivative DP1 could explain the presence of the degradation product DP2.

Even though these two peaks were not separately observed in the HPLC-DAD, their appearance when using the UPLC-QTOF-MS ${ }^{\mathrm{E}}$ technique is justified by the higher chromatographic resolution of the UPLC system compared to the HPLC-DAD technique. This is supported by the $\mathrm{m} / \mathrm{z}$ found for the degradation products (mass error $<5 \mathrm{ppm}$ ). The DPs suggested in this analysis are in agreement with the theoretical data defined by the software Zeneth. ${ }^{20}$

\section{Acidic condition}

Regarding acid hydrolysis, BNZ was subjected to degradation reaction with $0.1 \mathrm{M} \mathrm{HCl}$ for a period of 7 days; however, this condition did not promote drug degradation. Then, BNZ was exposed to more concentrated acidic solutions (1 and $2 \mathrm{M} \mathrm{HCl}$ ). A chromatographic peak (HPLC-DAD) at the retention time of 1.96 min could be observed after $96 \mathrm{~h}$ under $2 \mathrm{M}$ hydrochloric acid condition, accompanied by a $20 \%$ decrease of the benznidazole peak area (see Figure S1b in SI section).

Chromatographic analysis was then performed with the UPLC-QTOF-MS ${ }^{\mathrm{E}}$ instrument. Likewise, for the HPLC-DAD analysis, a new peak was observed, in this case with a retention time of $2.79 \mathrm{~min}$, which exhibited a precursor ion at $\mathrm{m} / \mathrm{z} 250.0747$ (positive mode), as shown in Figure 5, indicating the molecular formula $\mathrm{C}_{12} \mathrm{H}_{12} \mathrm{~N}_{3} \mathrm{OCl}$ (error less than $5 \mathrm{ppm}$ ).

The collision induced dissociation spectrum was also recorded, which presented typical fragments, such as $\mathrm{m} / \mathrm{z} 91.0548$ and 148.1819. The proposed structure of the pseudo degradation product obtained under acidic conditions is represented in Figure 6, which was named $\mathrm{N}$-benzyl-2-(chloro-2,3-dihydro- $1 \mathrm{H}$-imidazol-1-yl) acetamide (DP3). Additionally, the isotope pattern matches the proposed structure due to the presence of the chlorine atom, as shown in Figure 6.

Based on the proposed chemical structure, the degradation pathway under acidic conditions was outlined (see Figure 7). After protonation of the nitrogen of the imidazole ring, the chloride ion in the medium would attack to the electron-deficient carbon attached to the nitro group. The re-aromatization of the imidazole ring would

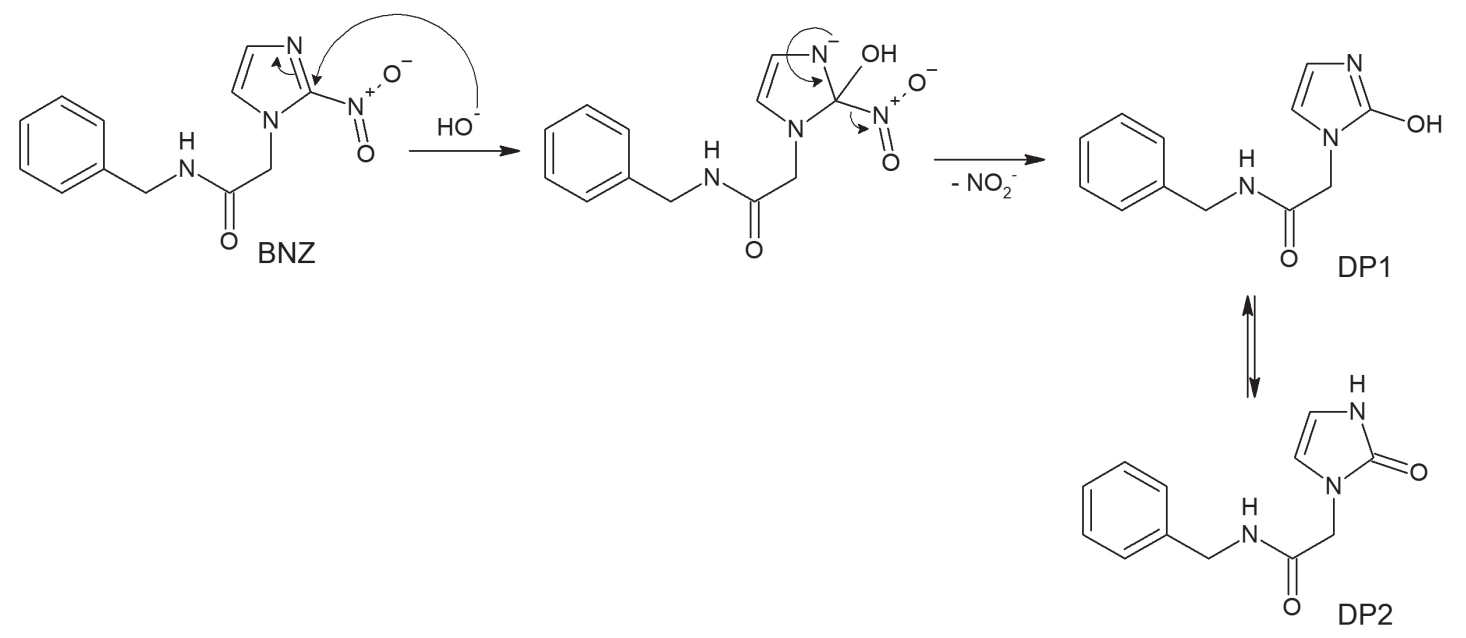

Figure 4. Suggested benznidazole degradation pathway under alkaline conditions. 
occur with the elimination of nitrous acid, leading to the chlorinated degradation product DP3.

\section{Acid condition}

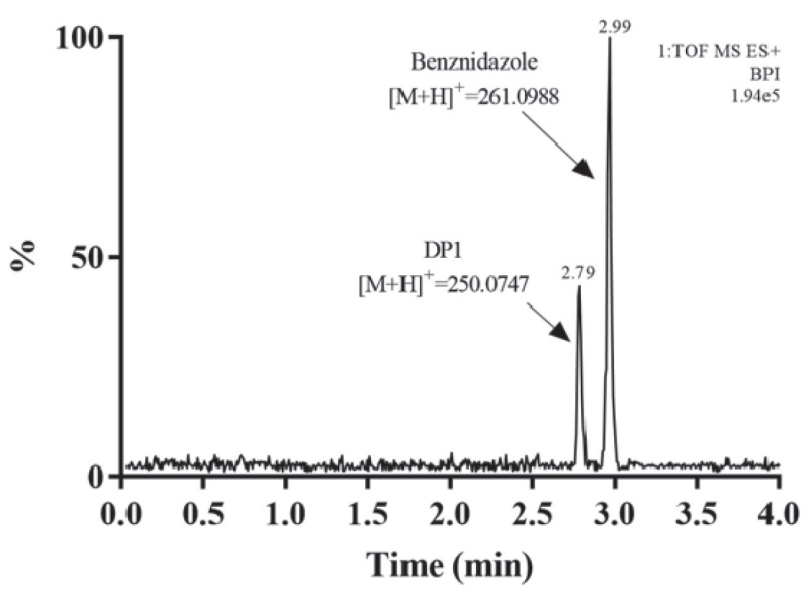

Figure 5. Chromatogram obtained for benznidazole after acid condition in UPLC-QTOF-MSE .

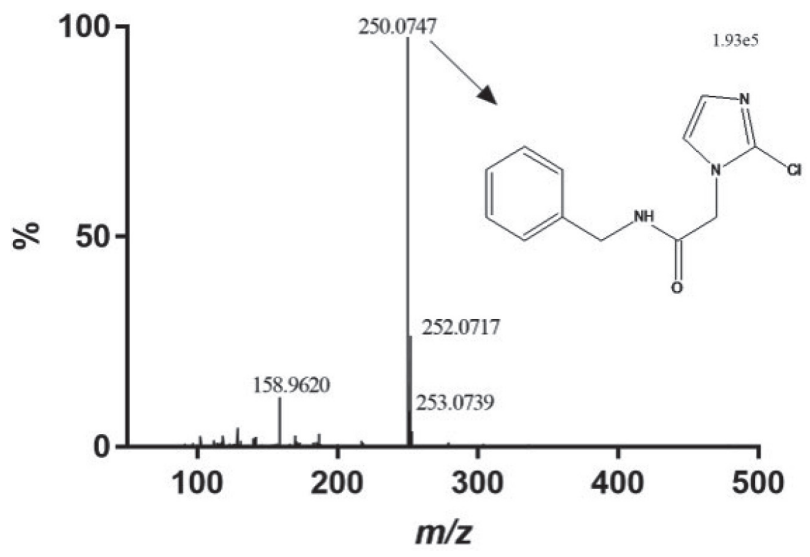

Figure 6. Spectrum with a chromatographic peak of $2.78 \mathrm{~min}$ and the suggested structure.
In order to confirm whether it was a degradation product or not, BNZ was tested in the presence of other acids. Sulfuric acid and hydrobromic acid were tested, however, the analyte did not degrade in the presence of these acids, confirming that this pseudo degradation product is dependent of the chlorine, as shown in the Figure 7.

\section{Thermal condition}

Benznidazole was stable under thermal degradation conditions (water bath at $60^{\circ} \mathrm{C}$ ). No additional peaks were detected in the analytical run in HPLC-DAD, and the BNZ peak appeared exactly at its retention time ( $7.15 \mathrm{~min})$ with an area similar to the standard at the same concentration. Due to the absence of new chromatographic peaks with this condition, the sample was exposed to a more extreme condition, $80{ }^{\circ} \mathrm{C}$, for a period of 7 days. Again, the appearance of new peaks was not observed, nor was there significant decay of the analyte peak area.

\section{Oxidation condition}

After $48 \mathrm{~h}$ of oxidative conditions, the sample was analyzed by HPLC-DAD, giving the chromatogram represented in Figure 8. Analysis gave no additional peaks, while BNZ was observed at 7.14 min with a similar peak area as the original solution. These results were predicted by Zeneth software ${ }^{20}$ for the simulation of the oxidation degradation reaction, showing no degradation products with this condition.

\section{Photolytic degradation}

After 14 days of exposure of the sample to the photolytic condition, no additional peaks appeared in chromatogram corresponding to possible degradation products (Figure 9).

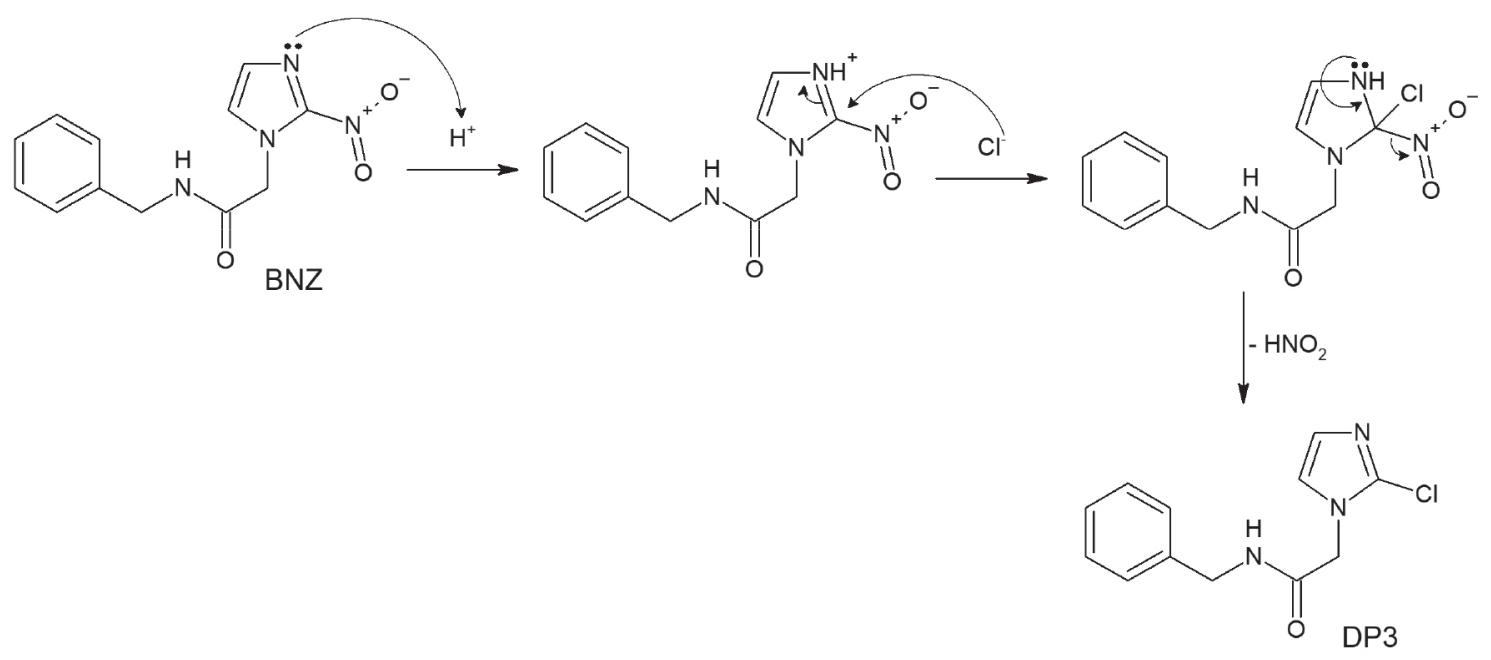

Figure 7. Suggested benznidazole degradation pathway under acidic conditions. 


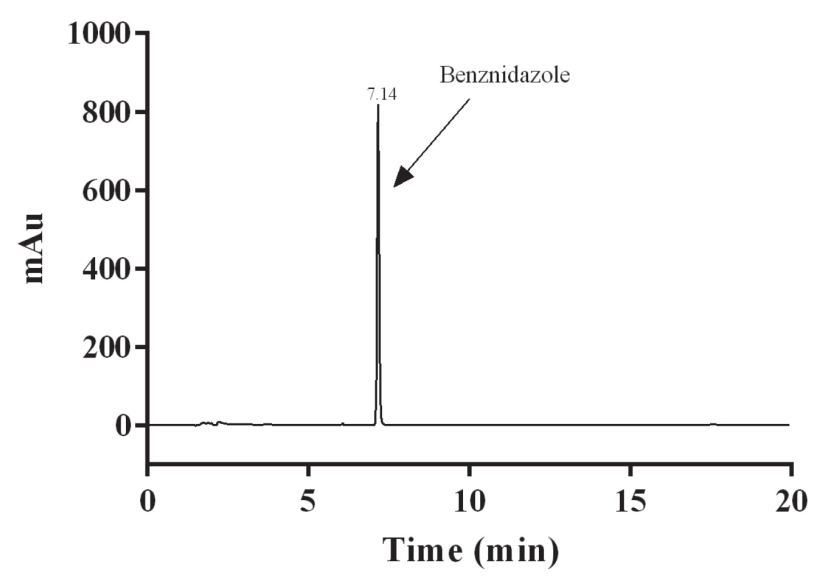

Figure 8. Chromatogram obtained for benznidazole after oxidative degradation in HPLC-DAD.

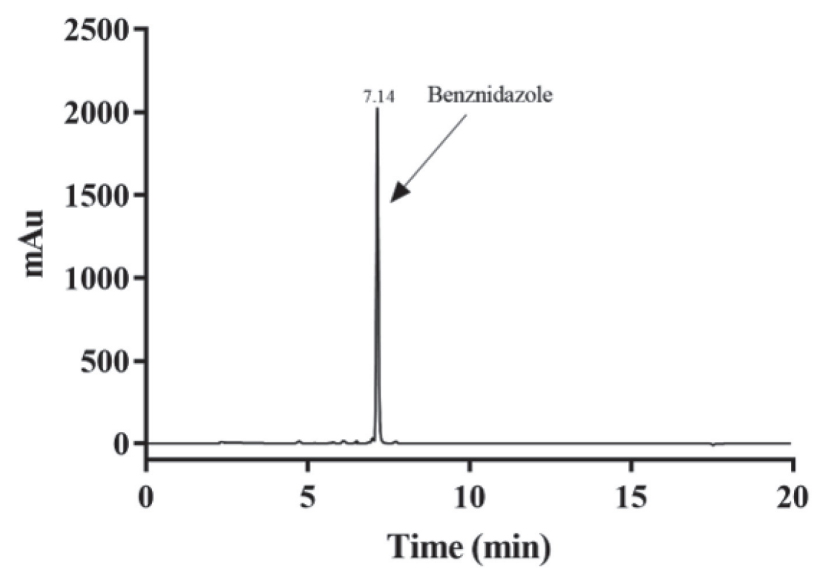

Figure 9. Chromatogram obtained for benznidazole after photolytic degradation in HPLC-DAD.

Once again, the area of benznidazole with this condition was similar to benznidazole in the initial condition.

\section{Method validation}

\section{Selectivity}

Selectivity is the ability of the method to differentiate the analyte in the presence of interferent signals, such as the DPs. As shown in the chromatogram (Figure 10) for the analysis of a sample composed of a mixture of the degradation products and benznidazole, no interfering peak was detected in the retention time of benznidazole. Furthermore, in the analysis of peak purity of BNZ and its DPs by ChemStation software, values higher than $99.0 \%$ were obtained. Figure S2 (SI section) shows the UV spectra of BNZ. Overall, this data demonstrated that the DPs did not compromise the analysis of BNZ, which means the method is selective.

\section{Lower limit of quantification}

Based on the calibration curve slope and standard

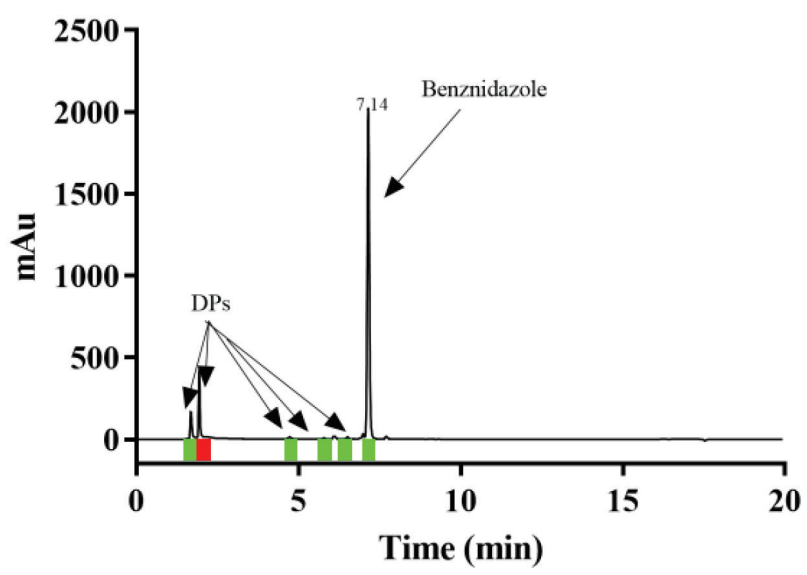

Figure 10. Chromatography representing the purity of peaks for the selective test.

error, the LOQ was calculated as $26.9 \mu \mathrm{g} \mathrm{mL} \mathrm{m}^{-1}$. Detailed results can be found in Tables S1, S2, and S3 (SI section). Furthermore, the lower point of the calibration curve $\left(180 \mu \mathrm{g} \mathrm{mL}^{-1}\right)$ presented satisfactory results, having a signal-to-noise ratio of more than 10 times and an RSD of 0.6639 .

Linearity

Linearity was observed in the concentration range $180-420 \mu \mathrm{g} \mathrm{mL}{ }^{-1}$, resulting in the linear equation $y=31.693 x+244.11$ (Figure S3, SI section). The correlation coefficient $(r>0.99)$ showed a significant correlation between the concentration and BNZ response in the detector, which was in agreement with the criteria of the guidelines used. ${ }^{26,27}$

The Cochran C test value obtained was 0.370 , which is lower than the critical value of 0.684 (five curve points and three replicates for the $y$ variable), establishing that the null hypothesis was acceptable and that the variations were homoscedastic. In addition, the $F$ value $(14,897.919)$ was greater than the critical value of 4.667 , leading to the conclusion that the proposed model is adequate to describe the phenomenon (Table S4, SI section). Also, the residual graph shows that there is a random distribution behavior with no trend (Figure S4, SI section).

\section{Precision and accuracy}

The results obtained for intra-day and inter-day precision are shown in Table S5 (SI section). In all instances, RSD values were less than $5 \%$ and the $p$-values were greater than 0.05 , confirming that the method is precise.

For the accuracy parameter, values greater than $99.2 \%$ recovery were acquired for the three concentration levels tested $(80,100$, and $120 \%)$, as demonstrated in Table S6 in SI section. Therefore, the method was considered accurate. 


\section{Robustness}

The results obtained for robustness tests are described in Table S7 in the SI section. The present method gave RSD values that did not exceed $5 \%$ and $p$-values that were higher than 0.05 , ensuring that the results are not considered statistically different for all modified parameters. Therefore, these small modifications did not compromise the analysis of the method.

\section{Matrix effect}

The matrix effect was determined by comparing the slope of two analytical curves, as suggested by ANVISA Guideline, ${ }^{26}$ the first constructed with the standard solution and the second with the diluted samples spiked with the analyte, both with the same concentrations (180-420 $\left.\mu \mathrm{g} \mathrm{mL}^{-1}\right)$. ANOVA statistical analysis, coefficients and the comparison test were also performed to verify the presence of the matrix effect. To evaluate this parameter, a significance level of 5\% was adopted in the null hypothesis test, and Excel software ${ }^{28}$ with the ActionStat supplement was used.

The results of the areas of the chromatographic peaks obtained for the analysis of this parameter are given in Table S8 in the SI section. Comparing the slopes of the lines (obtained through the curve in the matrix and in solution), a parallelism relation is observed, indicating the absence of interference of the constituents of the matrix (Figure S5, SI section).

ANOVA statistical analysis, coefficients, and the comparison test can be visualized in Tables S9, S10, and S11 in SI section, respectively. The $p$-value obtained in the tests was lower/higher than $5 \%$, proving that there is no significant difference between the curves with and without matrix.

\section{Conclusions}

In summary, forced degradation assays demonstrated that BNZ is unstable in the alkaline media employed and moderately stable under acidic conditions. Under thermal, oxidative and photolytic conditions, BNZ was stable. Three degradation products from BNZ were identified and their structures were proposed based on mass determination by UPLC-QTOF-MS ${ }^{\mathrm{E}}$ technique and Zeneth software. $N$-Benzyl-2-(2-hydroxy-1H-imidazol-1-yl)acetamide (DP1) and $\mathrm{N}$-benzyl-2-(2-oxo-2,3-dihydro- $1 \mathrm{H}$-imidazol1-yl)acetamide (DP2) would be formed under alkaline conditions, while $N$-benzyl-2-(chloro-2,3-dihydro$1 \mathrm{H}$-imidazol-1-yl)acetamide (DP3) would be formed under acidic conditions.

The HPLC-DAD stability indicating method proved to be adequate for the quantification of benznidazole. The parameters established in the validation demonstrated that the method is selective, linear, precise, accurate, free of matrix effects, and it is robust. Therefore, the new method could be employed in future analyses of stability tests.

\section{Supplementary Information}

Supplementary data are available free of charge at http://jbcs.sbq.org.br as PDF file.

\section{Acknowledgments}

The authors would like to thank Coordenação de Aperfeiçoamento de Pessoal de Nível Superior (CAPES), and Conselho Nacional de Desenvolvimento Científico e Tecnológico (CNPq) for the scholarship. The authors also wish to acknowledge the CP 01/2016 Programa Pesquisa para o Sistema Único de Saúde: Gestão Compartilhada em Saúde - PPSUS Edição 2015 Fundação Araucária-PR/SESA$\mathrm{PR} / \mathrm{CNPq} / \mathrm{MS}-\mathrm{Decit}$ (CV 45) for the valuable contribution.

\section{References}

1. Filho, J.; Vieira, M. C.; Xavier, I. G. G.; Maciel, E. R.; Junior, L. F. R.; Curvo, E. O. V.; Pereira, I. M.; Quintana, M. S. B.; da Silva, G. M. S.; Veloso, H. H.; Mendes, F. S. N. S.; HasslocherMoreno, A. M.; de Sousa, A. S.; do Brasil, P.; Saraiva, R. M.; Mediano, M. F. F.; Trop. Med. Int. Health 2018, 23, 1213.

2. Moncayo, A.; Mem. Inst. Oswaldo Cruz 1999, 94, 401.

3. Valdez, R. H.; Tonin, L. T.; Ueda-Nakamura, T.; Silva, S. O.; Dias Filho, B. P.; Kaneshima, E. N.; Yamada-Ogatta, S. F.; Yamauchi, L. M.; Sarragiotto, M. H.; Nakamura, C. V.; Antimicrob. Agents Chemother. 2012, 56, 507.

4. Ribeiro, A. L. P.; Rev. Soc. Bras. Med. Trop. 2018, 51, 413.

5. Schmunis, G. A.; Yadon, Z. E.; Acta Trop. 2010, 115, 14.

6. Barbosa, M. P.; Carmo, A. A.; Rocha, M. O.; Ribeiro, A. L.; Rev. Soc. Bras. Med. Trop. 2015, 48, 4.

7. Benziger, C. P.; do Carmo, G. A. L.; Ribeiro, A. L. P.; Cardiol. Clin. 2017, 35, 31.

8. de Bona, E.; Lidani, K. C. F.; Bavia, L.; Omidian, Z.; Gremski, L. H.; Sandri, T. L.; Reason, I. J. M.; Front. Immunol. 2018, 9 , 1842.

9. Perez-Molina, J. A.; Molina, I.; Lancet 2018, 391, 82.

10. de Andrade, J. P.; Marin Neto, J. A.; de Paola, A. A. V.; VilasBoas, F.; Oliveira, G. M. M.; Bacal, F.; Bocchi, E. A.; Almeida, D. R.; Fragata Filho, A. A.; Moreira, M. C. V.; Xavier, S. S.; de Oliveira Jr., W. A.; Dias, J. C. P.; Arq. Bras. Cardiol. 2011, 96, 434.

11. Perez-Molina, J. A.; Perez-Ayala, A.; Moreno, S.; FernandezGonzalez, M. C.; Zamora, J.; Lopez-Velez, R.; J. Antimicrob. Chemother. 2009, 64, 1139. 
12. Pinazo, M. J.; Munoz, J.; Posada, E.; Lopez-Chejade, P.; Gallego, M.; Ayala, E.; del Cacho, E.; Soy, D.; Gascon, J.; Antimicrob. Agents Chemother. 2010, 54, 4896.

13. Blessy, M.; Patel, R. D.; Prajapati, P. N.; Agrawal, Y. K.; J. Pharm. Anal. 2014, 4, 159.

14. Alsante, K. M.; Ando, A.; Brown, R.; Ensing, J.; Hatajik, T. D.; Kong, W.; Tsuda, Y.; Adv. Drug Delivery Rev. 2007, 59, 29.

15. Bakshi, M.; Singh, S.; J. Pharm. Biomed. Anal. 2002, 28, 1011.

16. Matthews, B. R.; Drug Dev. Ind. Pharm. 1999, 25, 831.

17. Soares-Sobrinho, J. L.; Soares, M. F. R.; Lopes, P. Q.; Correia, L. P.; de Souza, F. S.; Macedo, R. O.; Rolim-Neto, P. J.; AAPS PharmSciTech 2010, 11, 1391.

18. Santos, F. L.; Rolim, L. A.; Figueiredo, C. B.; Lyra, M. A.; Peixoto, M. S.; Ferraz, L. R.; Soares-Sobrinho, J. L.; de Lima, A. A. N.; Leite, A. C. L.; Rolim Neto, P. J.; Drug Dev. Ind. Pharm. 2015, 41, 63.

19. MassLynx ${ }^{\text {TM }}$ NT4.1 Software; Waters Co., Milford, USA, 2014.

20. Zeneth, version 7.1.3; Lhasa Limitee, United Kingdom, 2019.

21. Agência Nacional de Vigilância Sanitária (ANVISA); Resolução da Diretoria Colegiada - RDC No. 53, de 4 de Dezembro de 2015, Estabelece Parâmetros para a Notificação, Identificação e Qualificação de Produtos de Degradação em Medicamentos com Substâncias Ativas Sintéticas e Semissintéticas, Classificados como Novos, Genéricos e Similares, e Dá Outras Providências; DOU 07/12/2015, republicada 08/12/2015, Brazil. Available at http://portal.anvisa.gov.br/documents/10181/3295768/\%28 1\%29RDC_53_2015_COMP.pdf/d38f507d-745c-4f6b-a0a6bd250f2e9892, accessed in December 2019.

22. International Conference on Harmonisation of Technical Requirements for Registration of Pharmaceuticals for Human Use (ICH); ICH Topic Q 1 A (R2) - Stability Testing of New Drug Substances and Products; ICH: London, UK, 2003.
23. ISO 10977:1993: Photography - Processed Photographic Colour Films and Paper Prints - Methods for Measuring Image Stability; International Organization for Standardization (ISO): Geneva, Switzerland, 1993.

24. Agência Nacional de Vigilância Sanitária (ANVISA); Guia para Obtenção do Perfil de Degradação, e Identificação e Qualificação de Produtos de Degradação em Medicamentos; ANVISA: Brasília, 2015. Available at http://portal.anvisa.gov. br/documents/10181/2738062/Perfil+e+produtos+de+degrada \%C3\%A7\%C3\%A3o+em+medicamentos.pdf/c18a4857-9a5c4292-a1bf-07af6cad6902?version=1.0, accessed in December 2019.

25. International Conference on Harmonisation of Technical Requirements for Registration of Pharmaceuticals for Human Use (ICH); Guidance for Industry - Q1B Photostability Testing of New Drug Substances and Products; ICH: Rockville, 1996.

26. Agência Nacional de Vigilância Sanitária (ANVISA); Resolução da Diretoria Colegiada - RDC No. 166, de 24 de Julho de 2017, Dispõe Sobre a Validação de Métodos Analíticos e Dá Outras Providências; DOU 25/07/2017, Brazil. Available at https://www20.anvisa.gov.br/coifa/pdf/rdc166.pdf, accessed in December 2019.

27. International Conference on Harmonisation of Technical Requirements for Registration of Pharmaceuticals for Human Use (ICH); Validation of Analytical Procedures: Text and Methodology Q2 (R1); ICH: Geneva, Switzerland., 2005.

28. Excel, Version 2016; Microsoft Corporation, Washington, USA, 2016.

Submitted: June 23, 2019

Published online: January 15, 2020 